\title{
Hiding In Plain Sight: Building Community Social Capital In Distance Education Graduate Programs
}

\author{
Brenda Helen Sheingold, George Washington University, USA \\ Joyce A. Hahn, George Washington University, USA \\ Anne Hofmeyer, University of South Australia, Australia
}

\begin{abstract}
There is an increasing global demand for a broad range of academic programs to be offered by distance education. The development of flexible online technology has made studying for a degree 'anywhere and anytime' possible and this option has significant appeal for many people. However, there is limited knowledge available to guide faculty in the strategic development of supportive learning environments for distance education students that fosters connectedness for academic success. The purpose of this three-phase study was to introduce the concept of community social capital to a cohort of graduate nursing students $(N=97)$ and then track implementation and impact in their on-line academic learning environment. Understanding social capital at the onset of graduate school can lead to an improved sense of how students can utilize and grow social capital, enhance bonding, and increase their academic advantage. The findings inform future education curricula, innovative strategies, and educational research agendas by suggesting that social capital awareness is beneficial to students enrolled in distance education.
\end{abstract}

Keywords: Cohort; Community; Distance Education; Graduate Education; Nursing; Social Capital

"Social capital is an advantage we need to grasp for success" Quote from new graduate school student

\section{INTRODUCTION}

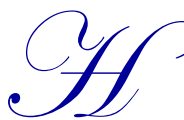

igher education has experienced a rapid paradigm shift from exclusively providing traditional classroom instruction to utilizing technology to expand distance education (DE). DE provides numerous benefits in terms of accessing educational opportunities across geographic boundaries and allowing time flexibility for full-time workers seeking new degrees. There are obstacles to overcome as DE expands; for example, Rovai \& Jordan (2004) report online students who have a low sense of community tend to feel isolated and are at risk for becoming dropouts. Increasing social presence within DE may create an enhanced perception of community and connectedness which translates into increased student interaction, decreases feelings of isolation, increases student retention, and suggests increased student satisfaction and learning outcomes (Mayne \& Wu, 2011; Francesato, et. al., 2006; Swan \& Shih, 2005).

Community social capital is defined as the quality and quantity of the social relations embedded within the community norms of interaction (Sheingold, 2009; Woolcock, 1998). These social relations are often intangible and affect the efficacy and quality of life in the community at multiple levels (Carlson \& Chamberlain, 2003; Sheingold, et.al., 2012). It can be found amid different nations, citizens and their homeland, in relationships with family members/friends, and between professionals and their vocation (Crow, 2002). Research conducted by Robert Putnam, Harvard University Professor of Public Policy, identified a declining trend in social networks/activities/trust, volunteer work, civic engagement, and organizational membership for the past 25 years and labeled this as a loss of social capital, which can lead to feelings of isolation (Putnam, 2000). DE can be an isolating experience if the faculty involved does not foster opportunities for students to collaborate in their learning journey (Nor, Hamat, \& Embi, 2012). 
This study examined one approach to investigate social capital as an unexplored phenomenon in DE in order to understand and build students' knowledge of the concept of social capital. This information can also inform the development educational tools for faculty to enhance social interactions in DE. The purposes of this study were to:

1. explore the attitudes and perception of DE graduate students regarding gaps in their understanding of social capital

2. facilitate support for community building and a foster a sense of belonging

\section{DESIGN}

The three-stage phase design utilized mixed methods and involved the administration of a six question online survey (Phase 1) developed to measure pre-existing social capital awareness, a four-question qualitative questionnaire (Phase 3) following a face-to-face information session about social capital, and another quantitative online survey (Phase 2) four weeks after DE course work began to track operationalization of the concept. All DE students attend a 2 day orientation workshop on campus that provides an introduction to their online program of study. This study was approved by the George Washington University Internal Review Board (IRB) and informed consent was obtained from all participants.

\section{METHODS}

\section{Participants}

The study employed a convenience sample of 97 new graduate students enrolled in DE nursing programs at The George Washington University School of Nursing starting in the 2012 fall semester. The demographic data revealed that $92 \%$ of the participants were female, $8 \%$ were male and that a total of $78 \%$ were below the age of forty. The largest percentage of participants held bachelor's degrees $(83.5 \%)$ followed by master's degrees (15.5\%) and $1 \%$ held a doctorate degree. The largest percentage of participants were employed full-time (79.4\%) and $17.5 \%$ were employed part-time.

\section{Phases 1 \& 3: Quantitative Data Collection}

An electronic survey was administered to elicit baseline data about the participants' understanding of the concept of community social capital and utility for their online education experience. Students were asked to complete this survey in the week prior to commencing their DE nursing program. Survey distribution occurred via the School of Nursing email list for incoming graduate students starting in the 2012 fall semester. Six questions from the Social Capital Integrated Questionnaire (SCIQ) were administered, employing one that represented each of the six dimensions of social capital as identified by World Bank (Grootaert, Narayan, Jones, 2004). The SCIQ is a widely acknowledged social science instrument with established validity and reliability that was purposefully designed for adaptation to acquire baseline data on social capital (Grootaert, Narayan, Jones, 2004). Table 1 displays the six dimensions of social capital and a related survey question that was designed to assess participant perception of social capital prior to the start of classes. The baseline social capital awareness perceived by participants was obtained utilizing a five-point Likert scale, with the higher total score indicating a higher degree of agreement with the variable.

\section{Phase 1: Results}

Data were analyzed using the Statistical Package for the Social Sciences (SPSS) 19. The six questions were coded so that higher scores reflected greater degrees of social capital and fewer concerns about the DE environment and learning. To assess the overall degree of social capital, a scale was created for values one and five by summing each of the respondent answers and dividing by the number of questions. The mean scale was 3.53, indicating a somewhat positive degree of social capital since 3 would be neutral. Responses to the first and third questions indicated some concern among respondents with the majority of responses either being neutral or disagree. For questions two, four, and five, the majority of responses either agreed (2 and 4) or disagreed (5) - both meaning 
student perceptions were positive toward social capital in distance learning. Respondents were neutral towards the use of social media possibly meaning the course tools for interaction were seen as sufficient.

Table 1: The Six Dimensions of Social Capital and Related Survey Questions

\begin{tabular}{|l|l|}
\hline \multicolumn{1}{|c|}{ Dimension of Social Capital } & \multicolumn{1}{c|}{ Related Survey Question } \\
\hline Groups and Networks & $\begin{array}{l}\text { 1.) I think there is no difference in the ability to work well with others } \\
\text { on joint projects in a distance education vs. live classroom setting. }\end{array}$ \\
\hline Trust and Solidarity & $\begin{array}{l}\text { 2.) I will feel safe expressing a different point of view in my distance } \\
\text { education classroom setting. }\end{array}$ \\
\hline Collective Action and Cooperation & $\begin{array}{l}\text { 3.) I think feelings of togetherness and closeness are part of the distance } \\
\text { education experience. }\end{array}$ \\
\hline Information and Communication & $\begin{array}{l}\text { 4.) Facebook and other social media will play a major role in how I } \\
\text { communicate with my distance education colleagues. }\end{array}$ \\
\hline Social Cohesion and Inclusion & 5.) Distance education is an isolating experience. \\
\hline Empowerment and Political Action & 6.) My participation and ideas will be valued and respected. \\
\hline
\end{tabular}

\section{Phase 3: Quantitative Data Collection}

Four weeks after the start of graduate classes, a second electronic survey was administered to the same group of participants $(N=97)$. The wording of the questions was modified slightly to reflect their actual experience and interaction in class. Table 2 demonstrates this adjustment.

Table 2: The Six Dimensions of Social Capital and Related Survey Questions - After 4 Weeks of Classes

\begin{tabular}{|c|c|}
\hline Dimension of Social Capital & Related Survey Question \\
\hline Groups and Networks & $\begin{array}{l}\text { 1.) I am experiencing minimal difficulty working well with others on } \\
\text { joint projects in a distance education setting. }\end{array}$ \\
\hline Trust and Solidarity & $\begin{array}{l}\text { 2.) I feel safe expressing a different point of view in my distance } \\
\text { education classroom setting. }\end{array}$ \\
\hline Collective Action and Cooperation & $\begin{array}{l}\text { 3.) I am experiencing feelings of togetherness and closeness as being } \\
\text { part of the distance education experience. }\end{array}$ \\
\hline Information and Communication & $\begin{array}{l}\text { 4.) Facebook and other social media play a major role in how I } \\
\text { communicate with my distance education colleagues. }\end{array}$ \\
\hline Social Cohesion and Inclusion & 5.) Distance education is an isolating experience. \\
\hline Empowerment and Political Action & 6.) My participation and ideas are valued and respected. \\
\hline
\end{tabular}

Phase 3: Results

The major findings from the follow-up survey were two-fold. First, the average social capital score increased somewhat (to 3.69). The difference was not tested for statistical significance because the surveys were not identified in a way that allowed for matching the pre and post scores for each respondent. Therefore, the paired $t$ test could not be applied. Second, responses on the first and third questions moved towards indicating more positive perceptions of social capital. For question one, the modal response changed from disagree to agree.

\section{Phase 2: Qualitative Data Collection}

The first (and perhaps only) time these DE students will meet face-to-face during the three-year period of their programs is during phase 2 of this study when they come on campus for the 2 day orientation workshops. A scripted PowerPoint presentation was delivered by the researchers during an on-campus orientation session to introduce the concept of community social capital and application in graduate education to the students participating 
in the study. Following the presentation, approximately 30 minutes was allowed for participant interaction and discussion. At the conclusion of this activity, a pen and paper evaluation was provided and participants were asked to answer two open-ended evaluative questions:

- $\quad$ Name three things you learned about social capital today.

- How do you think building social capital will help you as you begin your distance education program?

\section{Phase 2: Qualitative Data Analysis}

We were interested in exploring how participants understood and experienced the phenomena (community social capital) in their everyday world in which they lived and studied. The focus of phenomenological research studies can be on experiences and meaning in order to identify what is unique about those experiences (Crotty, 1998). Notably, phenomenon is real to the participants. Research relating to phenomenology can only be understood through studying the subjective perceptions of participants, such as the graduate students in our study. Therefore, our questions were posed to explore the meaning of community social capital for the participants in their everyday study life. Qualitative data were analyzed through the process of inductive reasoning to generate ideas from the data (Schneider et al, 2013). This process was undertaken independently by each researcher to identify potent verbatim quotes and scenarios to inform themes that illustrated how community social capital was understood by the graduate students. Insights were confirmed through a process of discussion and further reading of the transcripts where indicated to reach final agreement. Participant responses were listed in an unordered manner and then grouped according to inductive categories.

Two themes emerged from this data analysis as presented in Tables 3 and 4. An overarching theme, "Understanding social capital at the onset of graduate school can lead to a better sense of how we can build it", was identified.

Table 3: Categorization of Responses to Open-Ended Question, "Name 3 things you learned about social capital today"

\begin{tabular}{|l|l|}
\hline \multicolumn{1}{|c|}{ Inductive Categories } & \multicolumn{1}{c|}{ Participant Responses } \\
\hline Hiding in Plain Sight & $\begin{array}{l}\text { The world is more inter-related than we acknowledge. } \\
\text { Social capital is inherent to the learning environment. } \\
\text { Social capital does exist (mentioned frequently). }\end{array}$ \\
\hline $\begin{array}{l}\text { Social Capital is a Leadership Tool } \\
\text { Necessary for Success }\end{array}$ & $\begin{array}{l}\text { Needed for success. } \\
\text { Can be a leadership tool. } \\
\text { Is performed without people even knowing it (mentioned frequently). } \\
\text { The sum of parts is greater than the whole. }\end{array}$ \\
\hline Social Capital Bridges Differences & $\begin{array}{l}\text { Life experience combines different types of social capital. } \\
\text { Permits you to "hear" different perspectives and cultural differences. } \\
\text { Recognizing different backgrounds can be beneficial. } \\
\text { Education provides the link despite differences. }\end{array}$ \\
\hline Connectedness & $\begin{array}{l}\text { Sharing common concerns \& fears. } \\
\text { Helps join us together to accomplish a common goal (mentioned frequently). } \\
\text { Connects people at various levels (mentioned frequently). } \\
\text { Connects people outside of the community. } \\
\text { Can help problem solve. } \\
\text { Helps develop alliances. }\end{array}$ \\
\hline Evolving Social Capital & $\begin{array}{l}\text { We build social capital every time we interact with our peers. } \\
\text { It is important to always build on existing social capital (mentioned frequently). }\end{array}$ \\
\hline
\end{tabular}

Findings confirm that the scripted PowerPoint presentation and facilitated discussion did raise the graduate students' awareness of the concept of community social capital and ways in which they could operationalize the concept to benefit their experience of studying at a distance. The responses from participants in this study showed 
they appreciated the benefits of keeping connected with others and sharing ideas, insights, and support with others in the study groups.

Table 4: Categorization of Responses to the Open-Ended Question,

"How do you think building social capital will help you as begin your distance education program?"

\begin{tabular}{|c|c|}
\hline Inductive Categories & Participant Responses \\
\hline What Social Capital Can Do For Me & $\begin{array}{l}\text { Collaboration will be improved (mentioned frequently). } \\
\text { Enriches academic experience (mentioned frequently). } \\
\text { Others with similar experiences will help me overcome my challenges (mentioned } \\
\text { frequently). } \\
\text { Provide support to finish the program (mentioned frequently). } \\
\text { Distance education without social capital can be isolating. } \\
\text { Distance education will feel more like a community. } \\
\text { Building social capital will help me identify others I can connect with from other } \\
\text { geographical areas and share regional issues. }\end{array}$ \\
\hline Communication & $\begin{array}{l}\text { Helps communication between classmates to: } \\
\text { - } \text { help each other } \\
\text { - } \text { make connections } \\
\text { - } \quad \text { ask questions (mentioned frequently) } \\
\text { - } \text { share stories } \\
\text { makes communication more personal }\end{array}$ \\
\hline $\begin{array}{l}\text { Networking } \\
\text { (how we can build social capital) }\end{array}$ & $\begin{array}{l}\text { Encourage geographical networking with peers (mentioned frequently). } \\
\text { Connect with classmates through social networking websites \& services (mentioned } \\
\text { frequently). } \\
\text { Create a global network of colleagues. } \\
\text { Discover new resources. }\end{array}$ \\
\hline Relationships & $\begin{array}{l}\text { Build relationships with professors (mentioned frequently). } \\
\text { Helps me connect to individuals that motivate me }\end{array}$ \\
\hline External Community & $\begin{array}{l}\text { Sharing diverse ideas and international/global perspectives (mentioned frequently) } \\
\text { Assess new ways of understanding communities outside of my profession. }\end{array}$ \\
\hline
\end{tabular}

Participants were able to identify perceived long-term benefits of operationalizing the concept as they began their graduate studies. Themes included the importance of connections and accessing on-going support in their study networks to ensure they completed the program and achieved academic success. This is a particularly significant insight - that participants thought social capital could mitigate feelings of isolation and possible intentions to drop out of graduate school. Previous research discussed the risk of students dropping out of school due to feelings of isolation (Mayne \& Wu, 2011; Francesato, et. al., 2006; Rovai \& Jordan 2004; Swan \& Shih, 2005). It is timely for faculty to take the lead and identify effective strategies that increase a sense of student connectedness to enhance learning and academic success.

\section{CONCLUSION}

This research introduced new graduate students enrolled in DE programs to a theoretical social concept to support the operationalization of a social structure that promotes connectedness, mitigates feelings of isolation, and potentially enhances the scholarly exchange necessary for academic success. The concept of community social capital offers a strategic foundation for faculty to construct an effective learning environment for graduate students enrolled in DE programs. Strategies coalesce around fostering connectedness, cooperation, mutual understanding, trust, and the networking necessary to unite students in their quest for academic achievement and well-being. 


\section{AUTHOR INFORMATION}

Brenda Helen Sheingold, Ph.D., is an Assistant Professor and Founding Faculty at the George Washington University School of Nursing. Prior to her faculty appointment at George Washington University, Dr. Sheingold held the position of Senior Project Manager, for the Quality Department at Kaiser Permanente Mid-Atlantic Region. She holds a Bachelor's degree in nursing from George Mason University, a Master's degree from the Johns Hopkins University School of Business and a Ph.D. in Nursing/Public Policy from George Mason University. She is responsible for curriculum development for the George Washington's doctoral and master's graduate degrees in health care quality, including a joint degree program with the National Committee for Quality Assurance (NCQA). Dr. Sheingold has been an invited delegate (four consecutive years) to the Transatlantic Expert's Forum on Health Policy, in Berlin, Germany, and is a Fellow and Distinguished Scholar in the National Academies of Practice. E-mail: bsheingo@email.gwu.edu (Corresponding author)

Joyce Hahn, Ph.D., is an Associate Professor and Founding Faculty at the George Washington University School of Nursing. Prior to her appointment at GWU, Dr. Hahn was the Assistant Dean for the Master's Division in the School of Nursing at George Mason University. Dr. Hahn is a recipient of the Virginia Nurses Association Nursing Health Care Public Policy Award (2009) and past Executive Director of the Nursing Alliance for Quality Care. She has extensive experience bringing together nurses to work in an effective and collaborative manner. Dr. Hahn has published several articles in peer reviewed journals including JONA, Nursing Economics, Nursing Management, MEDSURG Nursing, Outcomes Management for Nursing Practice and The Journal for Healthcare Quality. Recently, she was extended a second gubernatorial appointment to the Virginia Board of Nursing for a four year term. Dr. Hahn is the immediate past Vice President of the Board of Nursing and has also served on the Joint Board of Medicine and Nursing for the Commonwealth of Virginia. Dr. Hahn brings extensive knowledge and expertise in nursing education, nursing administration, management, policy and health care delivery issues. E-mail: jhahn1@gwu.edu

Anne Hofmeyer, Ph.D., is Program Director, Higher Degrees by Research in the School of Nursing and Midwifery at the University of South Australia in Adelaide, Australia. She earned a PhD and a Master's Degree in Primary Health Care (Palliative Care) from Flinders University, Adelaide, Australia and completed an Intensive Bioethics Course at the Joseph \& Rose Kennedy Institute of Ethics, Georgetown University, Washington DC. She teaches in the undergraduate and postgraduate programs, is an active peer reviewer for Australian and international journals, published widely, and presented at state/provincial, national and international conferences. In 2005 she was awarded a two year Postdoctoral Fellowship funded by the Canadian Health Services Research Foundation (CHSRF) \& Canadian Institutes of Health Research (CIHR) CADRE Program and the Knowledge Utilization Studies Program, University of Alberta, Canada. In January 2012, she was appointed to the Research and Scholarship Advisory Council for The Honor Society of Nursing, Sigma Theta Tau International (STTI), Indianapolis, Indiana USA. E-mail: Anne.Hofmeyer@unisa.edu.au

\section{REFERENCES}

1. Carlson, E.D., and R.M. Chamberlain. (2003). Social capital, health and health disparities. Journal of Nursing Scholarship 35:4, 325-331.

2. Crotty, M. (1998). The foundations of social research: Managing and perspective in the research process, Allen \& Unwin, St Leonards, NSW.

3. Crow, G. (2002). The relationship between trust, social capital, and organizational success. Nursing Administration Quarterly, 26(3) 1-11.

4. Francescato, D., Mebane, M., Purcelli, R., Attanasio, C., \& Pulino, M. (2007). Developing professional skills and social capital through computer supported collaborative learning in university contexts. International Journal of Human-Computer Studies, 65, 140-152.

5. Grootaert, C., Narayan, D., Jones, V., Woolcock, M. (2004). Measuring social capital an integrated questionnaire. World Bank Working Paper No. 16. The World Bank. Washington, D.C.

6. Mayne, L.A. \& Wu, Q. (2011). Creating and measuring social presence in online graduate nursing courses. Nursing Education Perspectives, 32:2, 110-114. 
7. Nor, N.F.M., Hamat, A. \&Embi, M.A. (2012). Patterns of discourse in online interaction: Seeking evidence of the collaborative learning process. Computer Assisted Language Learning, 25:3, 237-256.

8. Putnam, R.D. 2000. "Bowling alone: The collapse and revival of American community." New York: Simon \& Schuster.

9. Rovai, A.P. \& Jordan, H.M. (2004). Blended learning and sense of community: A comparative analysis with traditional and fully online graduate courses. International Review of Research in Open and Distance Learning,5. Retrieved from http://www.irrodl.org/index.php./irrodl/article/view/192/274

10. Schneider Z. Whitehead, D. Lo-Biondo-Wood, G. Haber J. (2013). Nursing and Midwifery Research: Methods and Appraisal for evidence-based practice. $4^{\text {th }}$ edition Mosby Elsevier Chatswood NSW, Australia.

11. Sheingold, B.H. (2009). Measuring the extent, distribution and outcomes of social capital in the nursing community. ProQuest Dissertation and Theses Database.

12. Sheingold, B.H. Hofmeyer, A., Woolcock. M. (2012). Measuring the nursing work environment: Can a social capital framework add value? World Medical and Health Policy 4:1, Article 3.

13. Swan, K. \& Shih, L. (2005). On the nature and development of social presence in online course discussions. Journal of Asynchronous Learning Networks, 9:3, 115-136.

14. Woolcock, M. (1998). Social capital and economic development: Toward a theoretical synthesis and policy framework. Theory and Society 27:2, 151-208. 
NOTES 